\title{
Wang Feiman's Home Economics Education Thought and Practice Research*
}

\author{
Fusen Liu \\ Research Department \\ Qingdao Institute of Technology \\ Qingdao, China 266300
}

\author{
Shujuan Wang \\ Jiaozhou No. 3 Middle School \\ Qingdao, China 266300
}

\begin{abstract}
Wang Feiman's home economics education thought originated from her interest in home economics education, the influence of family education, and her experience in studying home economics abroad. Her home economics education thoughts mainly include: "There is a need to preserve the crafts in the family", "The happiness of a family must be based on the happiness of the society", "To save the crisis of the nation, the most fundamental way is to cultivate sound nationals", "in the period of anti-Japanese war and the founding of China, women should at least have the ability to live independently". And she earnestly practiced what she had advocated. Wang Feiman took the employment as the basis of home economics education thought and pursued female independence. However, the substantive connotation of gender equality needs to be further explored, reflecting the entanglement between tradition and modernity.
\end{abstract}

Keywords-Wang Feiman; home economics education; gender equality

\section{INTRODUCTION}

Wang Feiman (1897-1977) was a female who came from Qihe County, Shandong Province. In 1923, she was admitted to the United States as an official student of Shandong Province. She received a bachelor's degree in chemistry from Macalester College in 1925, a bachelor's degree in home economics from the University of Minnesota, and a master's degree in home economics from Columbia University in 1931. She had taught home economics at Hebei Women's Normal College (the current Hebei Normal University), National Xi'an Temporary University, National Northwest United University, and Northwest Normal University. Shee settled in the United States in 1949 and died of illness in the United States in December 1977. Wang Feiman, as the first female official scholar in Shandong Province and the first female professor to start the school of home economics, holds an important position in the history of education in the Republic of China. However, academics are not paying enough attention. There is only one article about Wang Feiman, that is, Li Yaoxi's "Wang Feiman, Shandong's First

*Project: Social Science Planning Project of Shandong Province "Research on the Modernity Significance of the Home Economics Education Thought of the Republic of China" (Project No.: 18CJYZ03).

CLC number: G529

Document identification code: A
Travelling Beauty Scholar" published in "CHUNQIU" in the second issue of 2011, and introduced her legendary life. The lack of research in academic circles is exactly the original intention of this article. Due to the lack of data and the restriction of the level, the author intends to do a simple orginization of Wang Feiman's home economics education thoughts to make a difference.

\section{Historical CAUSES OF WANG FeIMAN'S Thoughts ON HOME ECONOMICS EDUCATION}

\section{A. Personal Interest}

Wang Feiman loved to be quiet since she was young. She often watched his mother sewing clothes or embroidery quietly. She would mend clothes around 6 years old. "While reading and literacy, she also learnt the sewing skills and needlework to the point of forgetting food and sleep." [1] Her love of housekeeping and her pursuit of new knowledge in her childhood made Wang Feiman have a strong interest in home economics.

\section{B. Family's Edification}

Wang Feiman was born in the family of education. Her father was Wang Zhuchen, a famous educator in Shandong Province. Wang Zhuchen vigorously advocated women's education, advocated gender equality, and advocated "election of outstanding women in vocational schools, plus a kind of training on disciplines similar to baby-sitter or home economics, etc., so that women can return home after school to teach kindergarten, or teach women's side jobs and help improve family education and so on. He also advocated to accelerate the implementation of women's education and the true equality to men."[2] $]^{202}$ Her father's ideas of women's education and vocational education had a great influence on Wang Feiman.

\section{Study Abroad Experience}

The family's democracy and her father's foresight allowed Wang Feiman to study in Jinan New School in 1918 , and then she was admitted to study chemistry at McAllester College in the United States as a student from Shandong University at full public expense. In 1925, she "was admitted to the University of Minnesota to study her favorite home economics", and after graduated, she "applied to the 
Department of Home Economics of Columbia University Teachers College." [3] American home economics education theory has a profound impact on it.

\section{WANG FEIMAN'S THOUGHTS ON FAMILY EDUCATION}

\section{A. "It Is Necessary to Preserve the Crafts in the Family"}

Household crafts are gradually declining in western countries, but there is a different situation in China: "The science is backward and the industry is weak. To prevent the huge outflow of cash, the craftsmanship in the family must be preserved." [4] As for what to preserve and how to preserve it depends on the economic situation, and it is necessary to make a distinguishment between urban and rural.

\section{B. "The Happiness of a Family Must Be Based on the Happiness of Society"}

Family life in China is mostly the inheritance of oral words, and the customs are common, lacking of correct modern knowledge, which all aspects show the phenomena of irrationality and waste. Therefore, it is necessary to carry out a thorough "scientific" transformation, that is, "life is related to health, economics, and noble ideals." [3] The family and society are connected. In the current time that social relations are becoming increasingly complex, "the happiness of a family must depend on the happiness of society". [4] It is impossible for a family to do everything in the society. It is necessary to participate in all kinds of social labor and work together. Wang Feiman criticized the current family for "lacking a social attitude, often unable to adjust to social life, and happening various disputes, which should be remedied." [4] Only by increasing the effectiveness of family life, will there be power to serve the society.

\section{C. "The Most Fundamental Way to Save the Nation's Crisis Is to Cultivate Sound Nationals"}

Children today are the masters of the country in the future. Only with the sound development of their wisdom, character, and physique, can they make a better contribution to the country when they become adults. However, Chinese people have ignored this, thinking that as long as they are a person, they seem to be qualified to raises. "As for how to raise and nurture, there is no preparation in advance, and no further research will be done later" [4], resulting in many physical or psychological defects in children. Therefore, the most fundamental way to save the nation's crisis is to cultivate sound citizens.

\section{D. "During the Anti-Japanese War, the Women Should Have at Least the Ability to Live Independently"}

Due to the lack of attention to home economics education, the independent living ability of girls is inadequate. "As a female student at a university, she won't even cook noodles by herself, then she can't enjoy her noodles. As for clothes that are worn or worn out, it is rare for girls to be able to sew themselves, and it is even more difficult to sew clothes by themselves. [5] From the perspective of the relationship between the family and the nation, "A family's internal assistance is not good, and it often hinders men's ability to serve the country. In the period of the War of Resistance against Japan, women should at least have the ability to live independently. Besides men, there are always worries that affect their contribution to the founding of the War of Resistance against Japan." [5] Of course, emphasizing family education is not to advocate that "every woman goes to study housework exclusively. Anyone who is a woman is given some basic housework training. It is not too much hope." [5]

\section{INITIATIVES TO PROMOTE HOME ECONOMICS EDUCATION}

\section{A. Establishing a Department of Home Economics at the University}

It is suggested that all normal colleges in the country should set up a home economics department to "bring up teachers for home economics education in secondary schools." The set-up home economics department should "focus on academic and applied research, such as food and nutrition, child rearing, family management, textiles and clothing, family art, and home economics teaching methods." [3] At the same time, the home economics department should be directly connected with the society, and should be responsible for "responsibility for family education in each district", and "establish a promotion department so that the research results can be contributed to society at any time", thus leading the scientific movement of families across the country, and creating happiness for the whole society.

\section{B. Implementation of the Home Economics Courses for Primary and Secondary Schools}

It is recommended that girls in primary and secondary schools and simple normal schools should attend the "courses of home economics". Teachers in the home economics course must be "quite qualified and should be perfunctory". In terms of teaching methods, it is necessary to avoid repeating what the book says. For various courses such as sewing and cooking, especially those with strong applicability, it will be a must to pay attention to "getting students interested" and cultivate their hands-on ability. [5] It should be noted that the difficulty of primary, junior and senior high schools should be focused and different. The home economics lessons in primary school should be simple, as long as "in terms of actual life, and explaining the three things: clothing, food, and living." The scope of home economics lessons in junior high school should be expanded, plus "simple courses in social sciences, such as practical economics, family and civics." High school's home economics lessons "should be transferred for the purpose of the student." Students in normal schools and simple normal schools must "specially focus on teaching methods and teaching materials"; ordinary high school students should "emphasize natural science (physics, chemistry, biology) and social science, history, sociology"; and those who do not want to teach after graduating from high school should "focus on practical applications." [3] 


\section{Expanding Publicity on Home Economics Education}

China's social education has always focused on men, not women. To correct this serious deviation, it is suggested that "home economics should be listed as a kind of social education". The common sense of home economics can be borne by social education, and it can be spread more quickly and widely. The first is that home economics education can be "radiated by family experts" and sometimes "movies can also be applied", which can present an "impression of specific home economics education". The second is to set up home economics guidance offices in different places, and to transfer the latest research results on home economics "by the home economics guidance to residents in different places". The third is to "expand the home economics column in newspapers and magazines to promote modern home economics knowledge." The fourth is to print and distribute home economics books and brochures. In practical terms, "the brochures are very powerful." [4]

\section{AN ANALYSIS OF WANG FEIMAN'S THOUGHTS ON HOME ECONOMICS EDUCATION}

\section{A. It Embodies the Entanglement Between Tradition and Modernity}

Wang Feiman's educational thoughts on home economics are deeply influenced by traditional culture, which reflects the idea of home and country; she also proposes a thorough "scientific" transformation of the family. It is believed that modern home economics education thoughts cannot be generated out of thin air and can only evolve gradually under the traditional background. Ancient Chinese home economics education and modern western home economics education thoughts may or should be integrated in a new context. This debugging mode of thinking essentially embodies the entanglement between tradition and modernity.

\section{B. The Purpose of Home Economics Education Is to Prepare for the Profession}

Wang Feiman believed that the purpose of home economics education is to prepare for the profession. Seeking employment opportunities is crucial for attracting people to learn home economics, and it also meets the government's goal of expanding employment and maintaining social stability. However, this view of the purpose of home economics education focuses more on the cultivation of vocational skills. It does not pay enough attention to family members' psychology, child development, husband and wife relationships, etc. As a result, its research content is narrowed, and it is greatly affected by market fluctuations, which is not conducive to the construction of subject knowledge system. Relatively speaking, the purpose of promoting family welfare is more scientific and reasonable. Home economics education should pay more attention to the acquisition of family benefits, the improvement of the quality of family life, and the establishment and maintenance of important values in family life.

\section{Substantive Equality of Male and Female Nationals Has Yet to Be Revealed}

Wang Feiman believed that "the most fundamental way to save the nation from perishing is to cultivate sound nationals" [3]. The dissemination of the concept of "nationals" is of great significance for deconstructing the "home-state" of the traditional ethical society and building a new type of "national-state" deconstruction. However, Wang Feiman's substantive equality of male and female nationals has yet to be further revealed, and "gender equality" ignoring the feminine traits is not the actual gender equality. Since the feminist movement in modern China was advocated and promoted by men, although they have paid more attention to thinking about issues from the standpoint of equality between men and women and focused on protecting women's interests, patriarchal consciousness has been intentionally or unintentionally incorporated into many claims of women's liberation, and women have expressed obedience to these claims. This was the limitation of that era.

\section{Only by Entering the Society to Seek Economic Independence, Can the Women's True Independence Be Achieved}

Gender theory, when studying the causes and mechanisms of gender role division such as "men outside, women inside", questioned the past that the division of labor was emphasized that the gender roles of men and women were mainly formed in the constraints of social culture and changed with the change of social culture. Gender can be constructed and therefore changeable. [5] $]^{3}$ This provides theoretical support for the achievement of equality between men and women. Wang Feiman believed that home economics education is a general education for ordinary women and a special education for home economics researchers. Home economics education is very beneficial to the future of women, and can give "women many familymanagement and professional conveniences" [3] such as "becoming a competent homemaker", "becoming an expert", "becoming an educator", "becoming a scholar of home economics for life", and "other professions".

\section{CONCLUSION}

In short, as long as women have family knowledge and skills, "economic independence is not a problem." [3] Obviously, Wang Feiman realized that only by going to society and seeking economic independence can women's true independence be achieved.

\section{REFERENCES}

[1] Li Yaoxi, Wang Feiman, Shandong's First Travelling Beauty Scholar [J]. CHUNQIU, 2011, 2: 23-24. (in Chinese)

[2] Wang Zhuchen, Universal Education Submission [A]. Wang Heng, Biography of Wang Zhuche, [C]. Jilin, Jilin People's Publishing House, 2004. (in Chinese)

[3] Wang Feiman, The Importance of Home Economics Education and Its Implementation [J]. Journal of Education, 1936, 26(12): 92-94. (in Chinese) 
[4] Wang Feiman, Home Economics Education in the Anti-Japanese War [J]. Education Communication Weekly, 1939, 2(15): 2-4. (in Chinese)

[5] Shen Yifei, Constructed Women [M]. Shanghai: Shanghai People's Publishing House, 2005. (in Chinese) 